NOTA

\title{
POTENCIALIDADE DO USO DA TERRA NA MICROBACIA HIDROGRÁFICA DO CÓRREGO DO CEVEIRO NA REGIÃO DE PIRACICABA ${ }^{1}$
}

\author{
Peterson Ricardo Fiorio,4*; José Alexandre M. Demattê2; Nagib Jorge Melém Júnior ${ }^{3,5}$; Jairo \\ Antonio Mazza ${ }^{2}$ \\ ${ }^{2}$ Depto. de Solos e Nutrição de Plantas - ESALQ/USP, C.P. 9 - CEP: 13418-900 - Piracicaba, SP. \\ ${ }^{3}$ Embrapa Amapá - C.P. 10 - CEP: 68906-970 - Macapá, AP. \\ ${ }^{4}$ Bolsista do CNPq. \\ ${ }^{5}$ Bolsista da Capes. \\ *e-mail: prfiorio@carpa.ciagri.usp.br
}

RESUMO: 0 objetivo do presente trabalho foi avaliar a ocupação agrícola da Microbacia Hidrográfica do Ceveiro para o ano de 1995 e estabelecer a sua potencialidade. Para tanto, foi utilizado o Sistema de Análise Ambiental para Planejamento Agrícola. A microbacia localiza-se na região de Piracicaba, SP, com aproximadamente 1990 ha. Predominam os Podzólicos e os solos Litólicos de textura média e argilosa. $\mathrm{O}$ uso da terra foi determinado por fotointerpretação, cujos os limites foram digitalizados e cruzados com os dados de declividade e solos, gerando mapas de intensidade de uso e aptidão agrícola. Os dados indicaram que apenas $27 \%$ da área da bacia estava sendo utilizada adequadamente, $48 \%$ estava sendo sub-utilizada e $23 \%$ excessivamente utilizada, com sérios riscos de degradação dos solos. As principais distorções observadas quanto ao uso da terra foram em relação a cultura da canade-açúcar, que ocupa áreas destinadas a cultura anual e pastagens.

Palavras-chave: aptidão agrícola, uso da terra, sensoriamento remoto

\section{LAND USE POTENTIAL IN THE CEVEIRO STREAM WATERSHED OF PIRACICABA}

ABSTRACT: The objective of this work was to evaluate the agricultural potential of the Ceveiro watershed Piracicaba, SP, Brazil, which contains 1990 ha considering available environmental conditions. Medium and clayey textured Ultisols and Entisols predominate. Land use was determined by remote sensing, the limits of the were digitalized and crossed with soils and shape data, using the Environmental Analysis System for Agricultural Planning. These results were then compared with the current land usage patterns that occurred in 1995, to determine if differences existed between current and prescribed land use. In $1995,48 \%$ of the area was being used below its potential use, $27 \%$ used appropriately, and $23 \%$ used with excessive intensity. The main difference in land use between the appropriately used and excessively used areas was due to sugarcane production.

Key words: agricultural potential, land use, remote sensing

\section{INTRODUÇÃO}

No Estado de São Paulo, a conscientização com a degradação ambiental tem aumentado nos últimos anos. O planejamento adequado da ocupação das terras é uma ferramenta básica para a conservação e preservação do ambiente.

Os diversos métodos utilizados para gerar dados como subsídios ao planejamento do uso da terra tem sido testados por diversos autores. Entretanto, segundo Assad (1995) os sistemas mais utilizados no Brasil para a avaliação da aptidão agrícola das terras são os sistemas de classificação da classe de capacidade de uso da terra (Lepsch et al. 1991) e o sistema de avaliação da aptidão agrícola das terras Ramalho et al. (1978).

Entretanto, tais sistemas apresentam componentes de julgamento muitas vezes

${ }^{1}$ Parte da Dissertação de Mestrado do primeiro autor apresentada à ESALQ/USP - Piracicaba, SP. 
subjetivos. Nesta área, Formaggio et al. (1992) já enfatizavam que um método mais realístico para se promover a adequação do uso da terra seria um sistema semi-automático e não subjetivo, onde a obtenção da aptidão agrícola estaria associada a verificação periódica do uso atual da terra e a comparação com a aptidão da mesma.

Koffler (1992) desenvolveu o sistema de Análise Ambiental para Planejamento Agrícola (SAMPA) que segue os fundamentos gerais dos trabalhos de levantamento de aptidão agrícola das terras, porém, com adaptações que permitem a automatização do sistema. O programa se utiliza de mapas de solo, declividade e uso atual, como também das características químicas e físicas dos solos. Essas informações são analisadas automaticamente e como resultados temos mapas de uso preferencial e intensidade de uso.

Koffler (1996) utilizando o SAMPA para estudo do uso da terra na Bacia do Rio Bauru, concluiu que ocorria uma grande ociosidade no uso da terra. As maiores distorções ocorriam em áreas indicadas para culturas de ciclo curto onde predominava a cana-de-açúcar. As culturas de ciclo longo (onde se inclui a cana-de-açúcar), as quais invadiam terras preferenciais para outros usos, tinham grande parte da sua área preferencial ocupadas por pastagens e silvicultura e somente as áreas recomendadas para silvicultura estavam sendo utilizadas adequadamente.

Portanto, o objetivo deste trabalho foi o de estabelecer a aptidão agrícola das terras para a Microbacia Hidrográfica do Ceveiro, localizada na região de Piracicaba, utilizando-se o programa SAMPA, de acordo com as condições ambientais disponíveis, e confrontar tais resultados com o uso e ocupação das terras dessa Microbacia em 1995, podendo assim, verificar as possíveis distorções existentes.

\section{MATERIAL E MÉTODOS}

Caracterização da área de estudo - A Microbacia Hidrográfica do Ceveiro (MHC), está limitada pelas coordenadas $22^{\circ} 47^{\prime} 00^{\prime \prime} \mathrm{S}$ e $47^{\circ}$ $47^{\prime} 00^{\prime \prime}$ W no Município de Piracicaba (SP), constituindo uma superfície de aproximadamente 1990 ha. A vegetação natural é do tipo Floresta mesófila semidecídua e o clima pelo sistema Köppen é mesófilo úmido sub-tropical (Cwa). A geologia da bacia está representada por rochas relacionadas com a Formação Corumbataí do
Grupo Passa Dois (siltitos, argilitos e folhelhos cinzentos a roxos, os quais dão origem a cerca de $67 \%$ dos solos da bacia), com arenitos da Formação Pirambóia e intrusivas básicas (Formação Serra Geral), ambas pertencentes ao Grupo São Bento (Instituto de Pesquisas Tecnológicas do Estado de São Paulo, 1981).

O relevo caracteriza-se por apresentar morros em cotas variando de 460 a $580 \mathrm{~m}$ de altitude, com relevo ondulado à forte ondulado. A declividade predominante nas encostas é de $10-15 \%$ e nos topos de $5 \%$. As áreas com declividade menores que $2 \%$ se encontram em pequenas várzeas e topos de alguns morros, constituindo menos de $5 \%$ da área total (Sparovek, 1991).

A área de estudo apresenta 9 classes de solos em 6 unidades de mapeamento de acordo com o mapa de solos obtido por Sparovek (1991) apresentadas na Figura 1.

1- Podzólico Vermelho-Amarelo de textura arenosa sobre média e/ou argilosa, de fertilidade variável, porém, quase sempre distrófico ou álico. São muito susceptíveis a erosão.

2- A Terra Roxa Estruturada foi grupada com o Podzólico Vermelho-Escuro argiloso e a Terra Roxa Podzólica. Tais solos são argilosos, bem drenados, de baixo gradiente textural e regra geral eutróficos. A área ocupada é pequena com 64 ha.

3- Podzólico Vermelho-Amarelo raso, corresponde aos solos desenvolvidos tanto dos arenitos como de material mais argiloso, muito erodidos, e de fertilidade variável e drenagem moderada. Corresponde a terceira unidade em área ocupada.

4- Solos Litólicos: são os mais abundantes na área, em torno de 903 ha, sendo predominantemente desenvolvidos de arenitos e/ ou folhelhos-siltitos.

5- Cambissolos: grupamento de solos mais profundos do que os solos Litólicos, porém, com elevado risco de erosão. A fertilidade é variável, assim como a textura e a drenagem.

6- A associação de solos Hidromórficos e/ou Aluviais ocupam as posições próximas aos cursos d'água, de drenagem lenta e fertilidade variável.

Metodologia: A metodologia utilizada encontrase disposta resumidamente na forma de um fluxograma na Figura 3. 


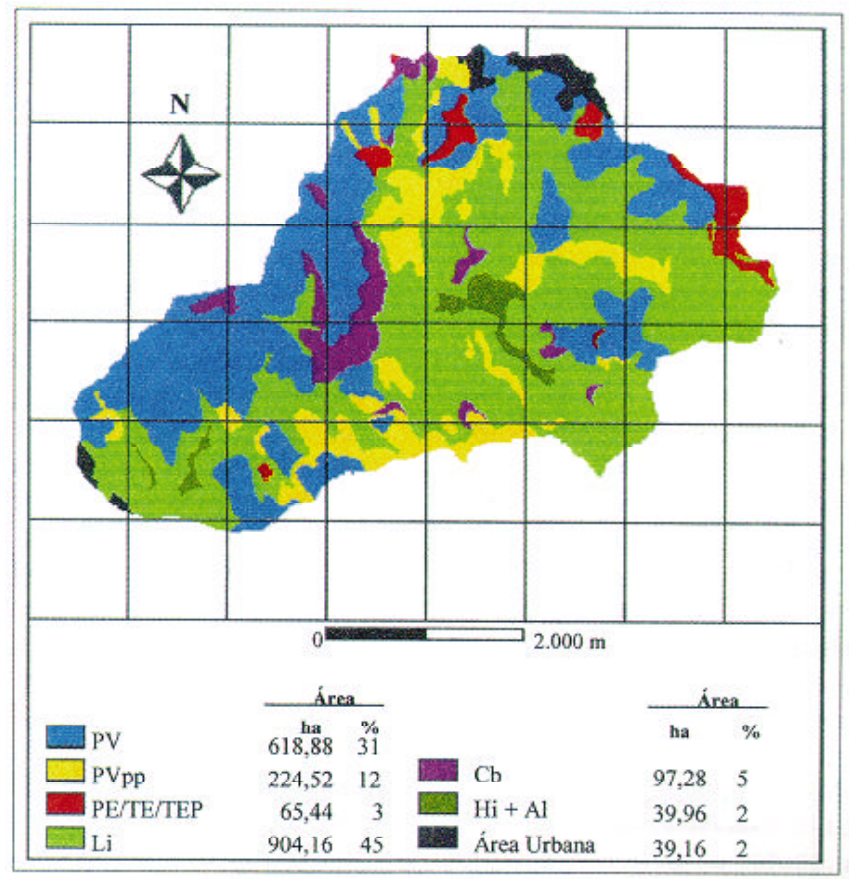

Figura 1 - Mapa pedológico reagrupado da Microbacia Hidrográfica do Córrego do Ceveiro, Piracicaba-SP.

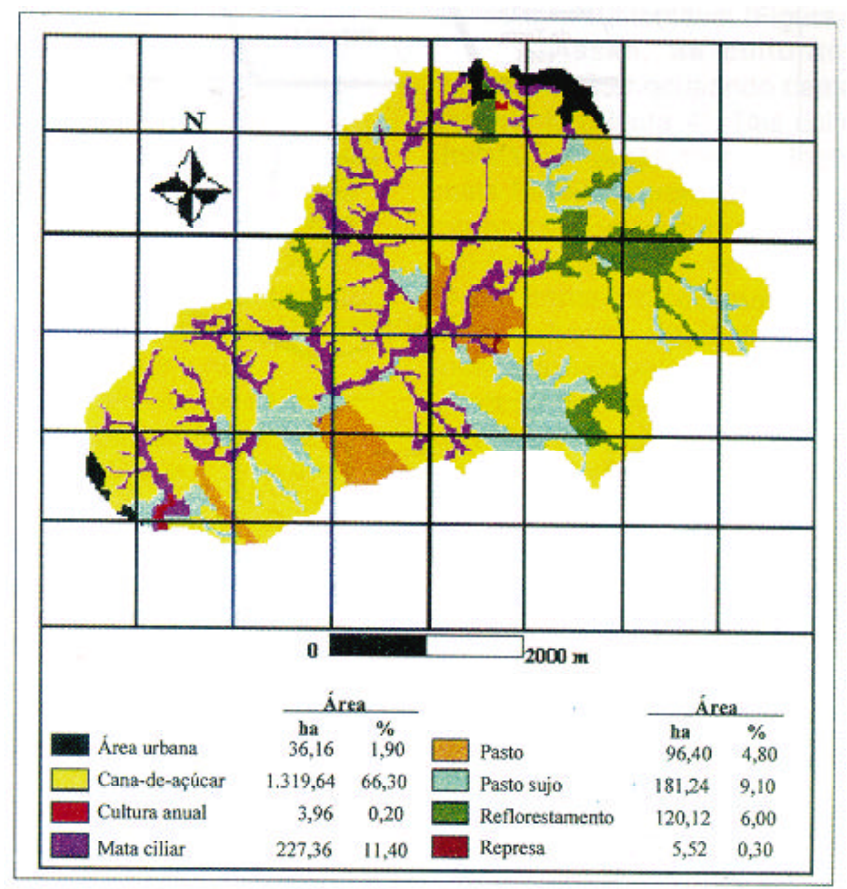

Figura 2 - Uso da terra na Microbacia Hidrográfica do Córrego do Ceveiro Piracicaba -SP em 1995. 
Foram utilizadas fotografias aéreas pancromáticas verticais do vôo aerofotogramétrico realizado no ano de 1995 na escala nominal de 1:25.000. A fotointerpretação foi realizada segundo metodologia descrita por Rabben (1960), delimitando-se, para cada par estereoscópico, a área útil das fotografias. Posteriormente, utilizou-se, de acordo com Anderson (1982), técnicas de overlay produzidos com folhas de acetato transparente com 0,10 milímetros de espessura, para a confecção do mapa de uso da terra de 1995. Para diferenciação de cada classe de uso da terra observou-se a textura, forma, telhado, aspectos associados entre outros (Figura 2).

O mapa de uso da terra obtido por fotointerpretação, a carta planialtimétrica e o mapa de solos, foram digitalizados no programa autocad e exportados para o Sistema de
Informações Geográficas (SIG), Idrisi (Eastman, 1992). Na seqüência, utilizou-se o Sistema de Análise para Planejamento Agrícola (SAMPA), o qual foi desenvolvido no IGCE-CEAPLA, na UNESP-Rio Claro, por Koffler (1992), que segue os fundamentos gerais de trabalhos de levantamento da aptidão agrícola das terras, como descritos por Ramalho et al. (1978) e Oliveira \& Berg (1985). O programa, após análises preliminares das limitações físicas e químicas dos solos e da declividade da área, organiza áreas de aptidão para quatro grupos de culturas (ciclo curto, ciclo longo, pastagem e silvicultura) promovendo uma adequação do uso da terra de forma semi-automática e não subjetiva.

Além disso, o programa possibilita através do cruzamento do mapa de uso atual e o de uso preferencial, gerar um mapa de intensidade de uso.

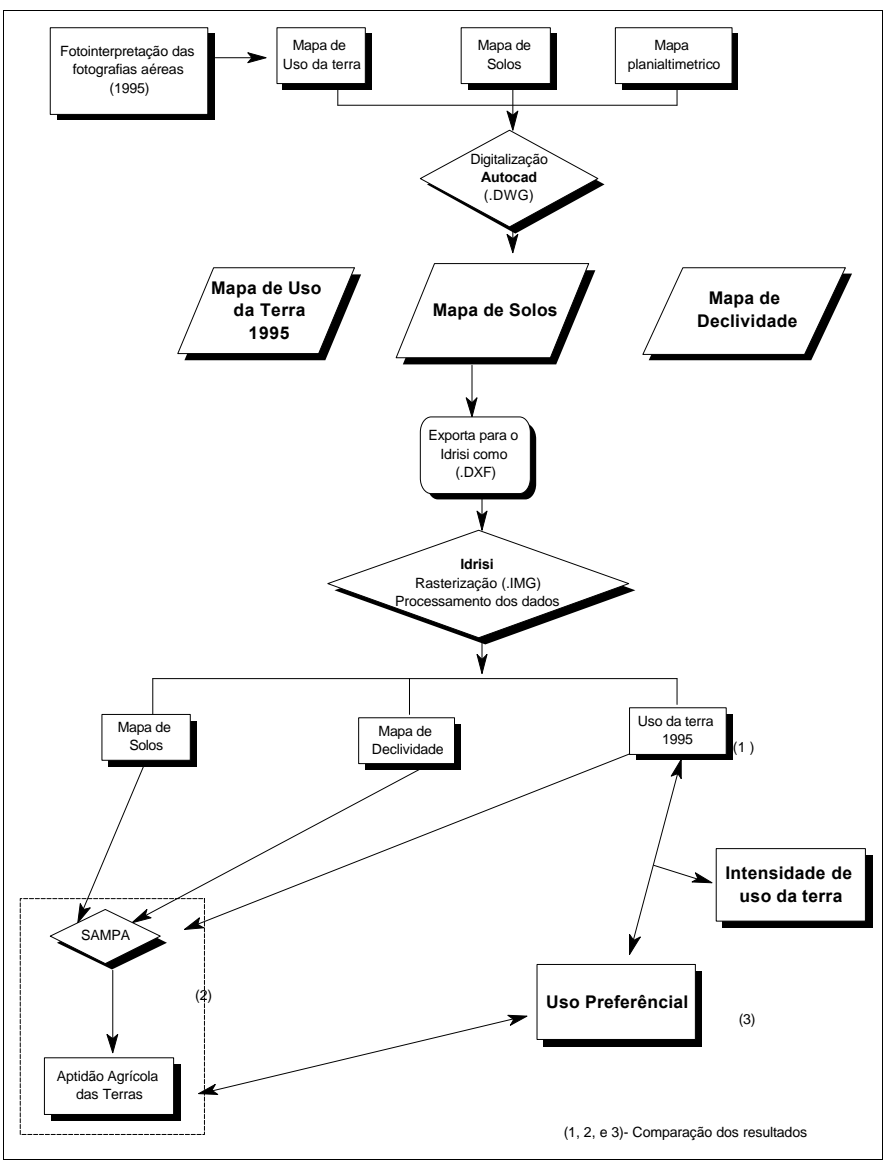

Figura 3 - Esquema da metodologia utilizada na Microbacia Hidrográfica do Córrego do Ceveiro. 


\section{RESULTADOS E DISCUSSÃO}

Aptidão agrícola ou potencialidade agrícola das terras: A Microbacia se caracteriza por apresentar uma pequena área com alta aptidão para ciclo curto (apenas $0,8 \%$ do total da MHC). Nesta condição, onde os fatores limitantes são de pequena intensidade e mais fáceis de serem manejados espera-se uma maior produtividade (TABELA 1).

A medida que há aumento nos fatores limitantes, a aptidão da MHC para ciclo curto diminui passando a ocupar 619,64 ha com aptidão regular e 1.315,00 ha com aptidão restrita. Mesmo utilizando-se de técnicas de manejo adequadas, essas áreas de aptidão regular e restrita apresentam baixa produtividade com alto risco de erosão (Lepsch et al., 1991).

Em relação as culturas de ciclo longo, as áreas de aptidão agrícola sugeridas pelo programa SAMPA, indicaram uma maior área de aptidão boa, porém ainda pouco expressiva, com 30 ha (TABELA 1). Para aptidão regular, a área é de 1.261 ha abrindo aí uma grande possibilidade de uso, principalmente para a cana-de-açúcar (semi-perene) ou outro tipo de cultura perene. Para um nível de aptidão restrita, a área já é bem menor do que para ciclo curto, no caso 660 ha.

As pastagens em relação as demais culturas, apresentaram as maiores áreas com aptidão boa, em torno de 335 ha, superior inclusive a silvicultura com 262 ha (TABELA 1).

Tal fato se deve seguramente ao maior porcentual de solos rasos (Cambissolos e Solos Litólicos) onde o desenvolvimento da cultura com raízes pivotantes é mais limitante (Figura 1).

A aptidão regular para a pastagem apresenta 1.479 ha, ainda assim, bem superior as demais culturas de ciclo curto e longo.

Tais resultados diferem dos obtidos por Koffler (1996) que trabalhou na Bacia do Rio Bauru, também área de solos Podzólicos e muitos susceptíveis a erosão. Tal autor, obteve maior aptidão para culturas de ciclo longo ao invés de pastagem. Isto se deve ao fato de ser a área trabalhada constituída por solos mais favoráveis e profundos no desenvolvimento da cultura da cana.

A área apresenta apenas 136 ha com aptidão restrita para pastagem, o que seguramente se refere as áreas mais declivosas e pedregosas, pouco apropriadas para pastagens e silvicultura, onde a mata deveria ter sido preservada.

Considerando-se a somatória das áreas com aptidão boa e regular a silvicultura ocuparia cerca de $93 \%$ do total da área da MHC (TABELA 1). A pastagem chegaria a ocupar $91 \%$, a cultura de ciclo longo $64,5 \%$ e as de ciclo curto apenas $32 \%$. As culturas de ciclo curto são as menos indicadas para o uso na MHC.

Uso preferencial das terras: Com o intuito de se obter um uso da terra que leve em consideração as qualidades e limitações das terras, para se manter a produtividade por um longo prazo, o programa SAMPA gerou um mapa que indicou qual a melhor distribuição e ocupação da área de estudo. Aliás, a posição de autores como Lepsch et al. (1991) são partidárias de que consideram o uso adequado da terra como sendo um dos primeiros passos para uma agricultura sustentável (Figura 4).

Assim, as culturas de ciclo curto poderiam estar ocupando cerca de $32 \%$ da área de estudo (Figura 4). Tais culturas tendem a se instalar em áreas menos declivosas e em solos mais férteis e profundos. Entretanto, as áreas ocupadas com culturas de ciclo curto perfazem em torno de $0,20 \%$ do total da área (Figura 2). $\mathrm{O}$ programa indicou que o restante das áreas com culturas de ciclo curto deveriam ser instaladas nos solos mais rasos, ou seja, os solos Litólicos que perfazem 45\%. Flores (1995) em seu trabalho sobre impactos ambientais e o uso agrícola dos solos, considerou determinados

TABELA 1 - Área da Aptidão Agrícola sugerida pelo programa SAMPA1.

\begin{tabular}{lrrrr}
\hline \multirow{2}{*}{ Classes de Aptidão } & \multicolumn{4}{c}{ Aptidão (SAMPA) } \\
\cline { 2 - 5 } & Ciclo Curto & Ciclo Longo & Pastagem & Silvicultura \\
\hline & 16,20 & 30,04 & 335,28 & 262,48 \\
Boa & 619,64 & $1.261,26$ & $1.479,52$ & $1.584,56$ \\
Regular & $1.315,40$ & 660,04 & 136,44 & 104,20 \\
Restrita & 39,16 & 39,16 & 39,16 & 39,16 \\
\hline Área urbana &
\end{tabular}

'Sistema de Análise Ambiental para Planejamento Agrícola, Koffler (1992).

${ }^{2}$ De acordo com Lepsch et al. (1991). 
solos Litólicos como possíveis de serem utilizados com culturas de ciclo curto, desde que tenham drenagem e espessura suficientes.

No caso específico da Bacia do Ceveiro, os solos mais rasos ocorrem também em relevo suave ondulado, persistindo assim, a drenagem superficial e evitando o encharcamento temporário.

As áreas ocupadas com culturas de ciclo longo (34,65\%) estão distribuídas praticamente em toda a bacia, porém, com maior concentração na área ao norte (Figura 4). Em tal região, há ocorrência dos agrupamentos dos solos Podzólicos nas suas diversas fases, assim como os Litólicos (Figura 1).

Tais resultados vêm confirmar o que grande parte dos produtores de cana e usinas da região tem feito. O plantio da cana-de-açúcar em solos rasos é facilitado pela própria natureza mais friável das rochas, no caso arenitos e folhelhos, não dificultando assim o processo de sulcamento que precede o plantio. Quanto aos solos podzolizados mais arenosos, o plantio no final do período chuvoso permite evitar os inconvenientes dos encharcamentos temporários e da erosão.

As áreas com pastagens estão também distribuídas por toda a bacia, concentrando-se também nestes dois solos, porém, em declividade mais acentuada. Tais resultados concordam com as observações de Flores (1995) que considera as culturas de ciclo longo e as pastagens aptas a ocuparem também solos podzolizados e solos Litólicos, desde que tenham declividades compatíveis.

A silvicultura, por sua vez, aparece em locais bem determinados na bacia e especificamente sobre os Cambissolos. Tais solos, sendo mais profundos que os solos Litólicos, favorece um melhor desenvolvimento radicular, assim como apresentam maior retenção de umidade. Este resultado corrobora o obtido por Flores (1995) que considera os Cambissolos mais apropriados para o reflorestamento.

Intensidade do uso da terra: $\mathrm{Na}$ comparação entre os mapas de uso preferencial das terras (Figura 4) e o uso da terra em 1995 (considerado como o uso atual) (Figura 2), o software SAMPA gera o mapa de intensidade de uso (Figura 5)

Com o mapa de intensidade de uso da terra, é possível avaliar as ações impostas pelo homem bem como o seu impacto ambiental na microbacia, como tem sido sugerido por Jenkins et al. (1994). Dentro desta mesma linha de trabalho, Bertolini, já em 1993, considerava as microbacias hidrográficas como a unidade que melhor tem refletido as ações antrópicas e seu impacto no ambiente.

O mapa de intensidade de uso (Figura 5) mostra a distribuição das áreas adequadamente utilizadas, as sub-utilizadas e as utilizadas acima do potencial natural. Do total da área, cerca de $17 \%$ apresenta uma utilização adequada e $23 \%$ está sendo utilizada acima de seu potencial. As áreas sub-utilizadas representam $48 \%$ do total da bacia.

A cana-de-açúcar é a grande responsável tanto pela utilização adequada como pela excessiva, já que a mesma ocupa em 1995 cerca de $66 \%$ da área (Figura 2).

As áreas sub-utilizadas (Figura 5) ocorrem principalmente nas áreas menos declivosas da microbacia, áreas estas que seriam mais indicadas para culturas de ciclo curto e longo assim como com pastagens, porém, estas áreas estão sendo utilizadas para a preservação de matas ciliares, junto aos canais de drenagem e cursos de água.

A TABELA 2 resume as áreas relacionadas ao uso da terra obtido em 1995 (Figura 2), assim como o uso preferencial (Figura 4) e a sua diferença.

Em relação a culturas de ciclo curto, a área está sendo sub-utilizada em 623 ha. Atualmente, grande parte da área é ocupada pela cana-de-açúcar no caso cultura de ciclo longo. Por outro lado, a cultura de ciclo longo está ocupando uma área atual de 1.319 ha contra um uso preferencial de 686 ha, ou seja, a cana-deaçúcar adentrou em áreas onde não deveria ter sido plantada. Essas áreas seriam destinadas a culturas anuais e pastagens. Fato que justifica as áreas sub-utilizadas (Figura 5). Tais resultados são diferentes dos obtidos por Koffler (1996) que observou que as maiores distorções existentes na bacia do Rio Bauru, ocorriam em áreas indicadas para ciclo curto e ocupadas por culturas de ciclo longo e pastagens.

As áreas de silvicultura não apresentaram diferenças entre 0 uso atual em 1995 e o uso preferencial (SAMPA), porém, o reflorestamento no uso atual ocupa áreas diferentes das propostas pelo uso preferencial.

Se for considerado que o uso preferencial seria o mais indicado para a ocupação adequada da bacia estudada, os dados (TABELA 2) indicaram que a cultura da cana-de-açúcar tem ocupado áreas onde não deveria ter sido plantada com sérios riscos de erosão e desequilíbrio ambiental. 


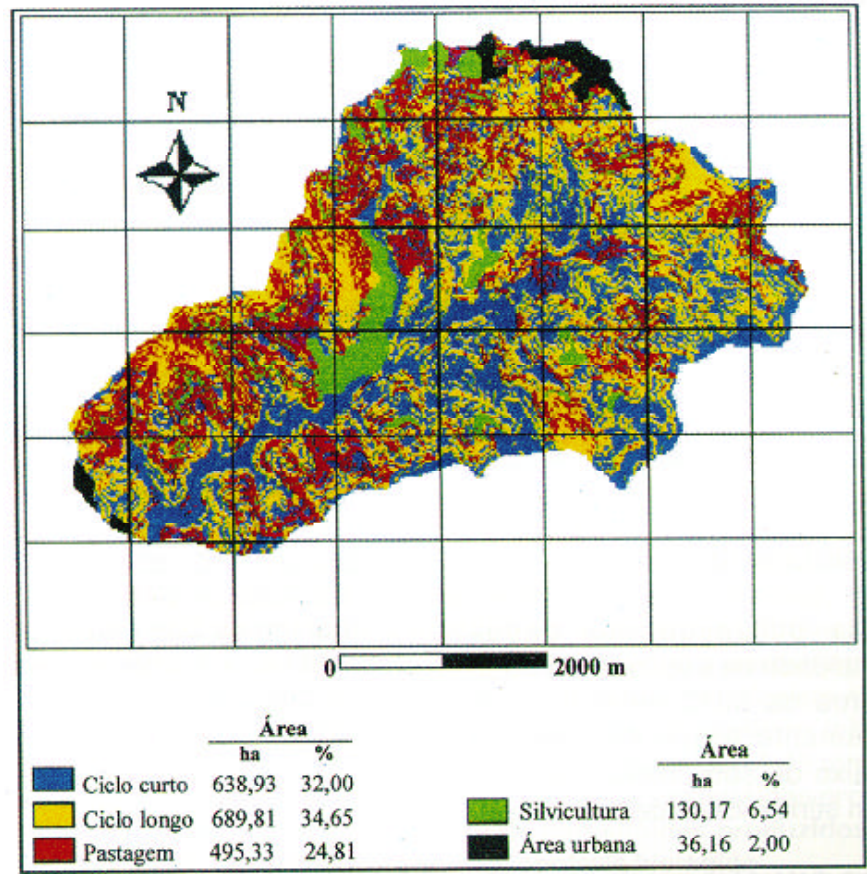

Figura 4 - Uso preferencial das terras na Microbacia Hidrográfica do Córrego do Ceveiro Piracicaba-SP.

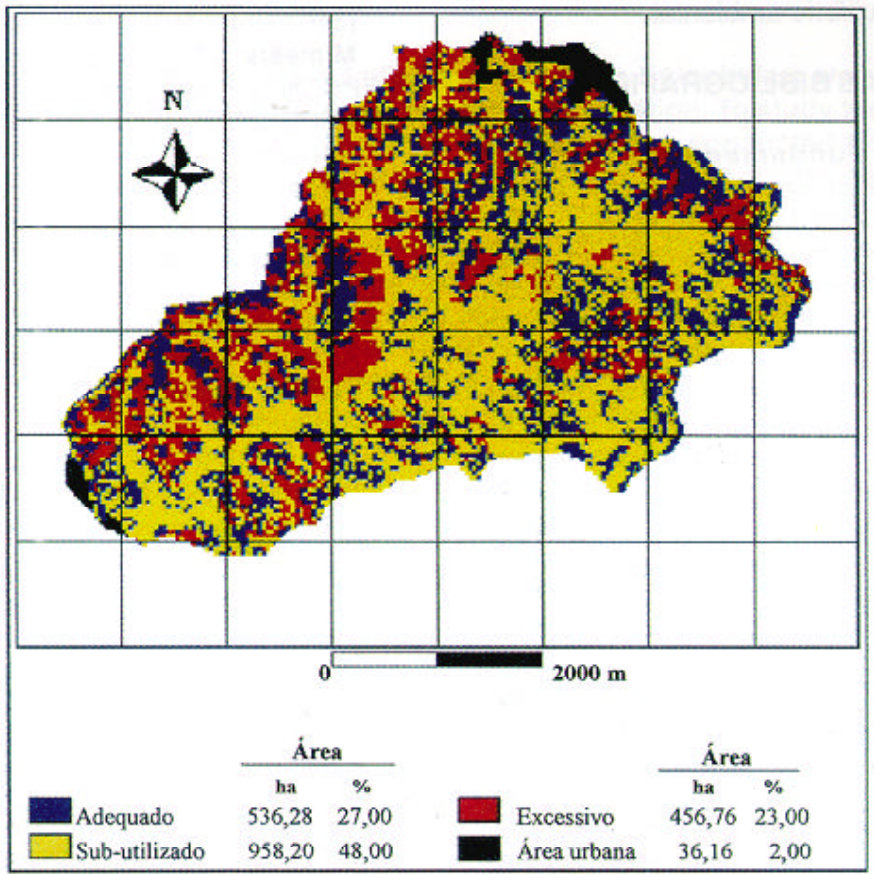

Figura 5 - Intensidade de uso das terras na Microbacia Hidrográfica do Córrego do Ceveiro Piracicaba-SP. 
TABELA 2 - Áreas de uso preferencial e uso da terra em 1995.

\begin{tabular}{lccc}
\hline Classes de Uso da Terra & Uso da terra 1995 & $\begin{array}{c}\text { Uso Preferencial } \\
\text { (SAMPA) }\end{array}$ & Diferença \\
\hline Ciclo curto & 2,96 & 635,84 & 632,88 \\
Ciclo longo & $1.319,64$ & 686,72 & 632,92 \\
Pastagens & 277,64 & 492,24 & 214,60 \\
Silvicultura & 120,12 & 127,08 & 7,08 \\
Mata ciliar & 227,36 & 0,00 & 227,36 \\
Área Urbana & 39,16 & 39,16 & 0,00 \\
\hline Total & 1990,40 & 1990,40 & \\
\hline
\end{tabular}

'Sistema de Análise Ambiental para Planejamento Agrícola, Koffler (1992).

\section{CONCLUSÕES}

Através da utilização dos dados relacionados a intensidade de uso, notou-se que apenas $27 \%$ da área da MHC estava sendo utilizada adequadamente e que $48 \%$ estava sendo utilizada abaixo de seu potencial e $23 \%$ excessivamente com sérios riscos de degradação dos solos.

As principais distorções quanto ao uso da terra foram devidas a cultura da cana-de-açúcar que invadiu áreas destinadas a culturas anuais e pastagem, concorrendo assim para a instalação de processos de desequilíbrio ambiental.

\section{REFERÊNCIAS BIBLIOGRÁFICAS}

ANDERSON, P.S. Fundamentos para fotointerpretação. Rio de Janeiro: Sociedade Brasileira da Cartografia, 1982. 136p.

ASSAD, M.L.L. Uso de uma sistema de informações geográficas na determinação da aptidão agrícola de terras. Revista Brasileira de Ciência do Solo, v.19, n.1, p.133-139, 1995.

BERTOLINI, F. Perspectivas de falta de madeira em futuro próximo. In: CONGRESSO FLORESTAL PANAMERICANO, 1., Curitiba, 1993. Anais. Curitiba: UFPR, 1993. v.3, p.40.

EASTMAN, J.R. Idrisi: user guide. Worcester: Clark University, 1992.

FLORES, M.X. Uso agrícola do solo: principais tipos de solo, potencial de utilização e impactos ambientais In: TAUK-TORNISIELO, S.M.; GOBBI, N.; FORESTI, C.; LIMA, T. M. Análise ambiental estratégias e ações. Piracicaba: T.A. Queiroz, 1995. cap.7, p.280-290.

FORMAGGIO, A.R.; ALVES, D.S.; EPIPHANIO, J.C.N. Sistemas de informação geográficas na obtenção de mapa de aptidão agrícola e taxa de adequação de uso das terras. Revista Brasileira de Ciência do Solo, v.16, n.2, p.249-256, 1992.
INSTITUTO DE PESQUISAS TECNOLÓGICAS DO ESTADO DE SÃO PAULO. Mapa geológico do Estado de São Paulo. São Paulo: IPT, DMGA, 1981a. v.1. 126p. Escala 1:500.00. (IPT, Monografia, 6).

JENKINS, A.; PETERS, N.E; RODHE, A. Hidrology. In: MOLDAN, B.; CERNY, J. (Coord). Biogeochemistry of small catchments: a tool for evironmental research. Chichester: Jonh Wiley, 1994. p.31-54.

KOFFLER, N.F. Sistema de análise ambiental para planejamento agrícola: versão 1.0. Rio Claro: CEAPLA, 1992. 41p.

KOFFLER, N.F. Uso das terras da Bacia do Rio Bauru (SP): situação atual e potencialidade agrícola. Mimesis, v.17, n.1, p.99-125, 1996.

LEPSCH, I.F. BELLINAZZI, J.R.; BERTOLINI, D.; ESPÍNDOLA, C.R. Manual para levantamento utilitário do meio físico e classificação de terras no sistema de capacidade de uso. Campinas: Sociedade Brasileira de Ciência do Solo, 1991. 175p.

OLIVEIRA; J.B.; BERG, M. Aptidão agrícola das terras do Estado de São Paulo: Quadricula de Araras:II. Memorial descritivo. Boletim técnico Instituto Agronômico, n. 102, p.60, 1985.

RABBEN, E.L. Fundamentals of photointerpretation In: AMERICAN SOCIETY OF PHOTOGRAMETRY. Manual of photographic interpretation. Washington, 1960. cap.3, p.99-186.

RAMALHO, A.; PEREIRA, E.G.; BEEK, K.J. Sistemas de avaliação da aptidão agrícola das terras. Brasília: EMBRAPA, 1978. 70p.

SPAROVEK, G. (Coord). Plano diretor da Microbacia do Córrego do Ceveiro Piracicaba: ESALQ, 1991. v.1, 286p.: Diagnóstico da situação, levantamento de problemas e propostas de solução.

Recebido para publicação em 19.08.98

Aceito para publicação em 13.09.99 